\title{
Characterization of Carboxylated Cellulose Nanocrystals from Recycled Fiberboard Fibers Using Ammonium Persulfate Oxidation ${ }^{1}$
}

\author{
Hossein KHANJANZADEH ${ }^{2}$ - Byung-Dae PARK (D) ${ }^{2, \dagger}$
}

\begin{abstract}
As a way of finding value-added materials from waste medium density fiberboard (MDF), this study characterized cellulose nanocrystals (CNCs) isolated by ammonium persulfate (APS) oxidation using recycled MDF fibers. Chemical composition of the recycled MDF fibers was done to quantify $\alpha$-cellulose, hemicellulose, lignin, nitrogen, ash and extractives. The APS oxidation was performed at $60{ }^{\circ} \mathrm{C}$ for $16 \mathrm{~h}$, followed by ultrasonication, which resulted in a CNC yield of $11 \%$. Transmission electron microscope images showed that rod-like CNCs had an average length and diameter of $167 \pm 47 \mathrm{~nm}$ and $8.24 \pm 2.28 \mathrm{~nm}$, respectively, which gave an aspect ratio of about 20 . The conductometric titration of aqueous CNCs suspension resulted in a carboxyl content of $0.24 \mathrm{mmol} / \mathrm{g}$ and the degree of oxidation was 0.04. Attenuated total reflection Fourier transform infrared (ATR-FTIR) spectroscopy clearly showed the presence of carboxyl group on the CNCs prepared by the APS oxidation. The change of $\mathrm{pH}$ of the aqueous CNC suspension from 4 to 7 converted the carboxyl group to sodium carboxylate group. These results showed that the APS oxidation was facile and CNCs had a one-step preparation method, and thus suggested an optimization of the oxidation condition in future.
\end{abstract}

Keywords: recycled fiber, cellulose nanocrystals, carboxylation, ammonium persulfate oxidation

\section{INTRODUCTION}

Medium-density fiberboard (MDF) is a type of wood-based composite panels that are widely used for the building and furniture industries. It is composed of refined wood fibers that have been pressed together under high temperature and pressure with a synthetic resin i.e. urea-formaldehyde (UF) resins to form a homogeneous board. The demand for MDF panels has significantly increased in recent years so that this growth in demand caused its worldwide production to be 93 million $\mathrm{m}^{3}$ in the 2017's (Haeldermans et al., 2019). In 2018, the MDF production in Republic of Korea was about $1,840,000 \mathrm{~m}^{3}$, which was ranked as the $9^{\text {th }}$ country in the world after China, Turkey, Brazil, Poland, Russia, Thailand, the United States and Belarus, respectively (FAO, 2019).

Due to this large volume of MDF production and the short life span of MDF panels compared to other building materials, it is expected to produce massive

\footnotetext{
${ }^{1}$ Date Received January 9, 2020, Date Accepted March 9, 2020

2 Department of Wood and Paper Science, Kyungpook National University, Daegu 41566, Republic of Korea

$\dagger$ Corresponding author: Byung-Dae PARK (e-mail: byungdae@knu.ac.kr, ORCID: 0000-0002-9802-7855)
} 
amounts of waste MDF. This increase in waste MDF requires an effective waste management system to alleviate issues without landfilling and combustion. Unfortunately, these wastes are usually incinerated or disposed to landfill sites (Lee et al., 2014; 2015), which consequently caused many environmental issues such as air pollution, greenhouse gas emissions, and the occupation of useful land. Therefore, finding a way of using these wastes is essential in the management of municipal solid waste (Seo et al., 2019). To alleviate environmental concerns about these wastes and add economic returns to the forest product industry, much research has been done in recent years and distinguishable progress has been achieved. The production of particleboard (Azambuja et al., 2018), wood-plastic composite (Krause et al., 2018), wood cement composite (Karade, 2010), activated carbon (Shang et al., 2014), biofuel via pyrolysis (Aslan et al., 2018), Bio-oil and biogas (Park et al. 2013), and dyed recycling wood fiber (Ju and Roh, 2017) from MDF wastes have been reported.

Production of cellulose nanocrystals (CNCs) from recycled MDF fibers can be an option. There is a growing interest in using CNCs derived from renewable and bio-sources (Kim and Kim, 2019). These nanoparticles can be used in combination with other materials to improve their performance or introduce new applications. $\mathrm{CNCs}$ are unique, renewable, biodegradable and nontoxic materials with exceptional mechanical properties (Cho et al., 2012; Khanjanzadeh et al., 2018; Park et al., 2014). These rigid rod-like CNCs display individual characteristics such as high aspect ratio (10-70), high specific surface area $\left(150 \mathrm{~m}^{2} / \mathrm{g}\right)$, high strength and modulus (10 and $150 \mathrm{GPa}$, respectively), and low density $\left(1.6 \mathrm{~g} / \mathrm{cm}^{3}\right)$ (Gwon et al., 2018; Khanjanzadeh et al., 2018). With such advantages, CNCs have been widely considered to have great potential applications in diverse fields, including reinforcement agent for films and nanocomposites, drug delivery systems, medical implants, conducting polymer nanocomposites, functional hydrogels, components in tissue engineering materials, protective coatings, supports for enzyme immobilization, etc. (Khanjanzadeh et al., 2018).

So far, two studies were carried out regarding the extraction of CNC from waste MDF (Couret et al., 2017; Gu et al., 2017). In both studies, sulfuric acid hydrolysis has been used for the isolation of CNCs. Acid hydrolysis is the most applied method to prepare CNCs from cellulosic fiber-based materials. The main challenges associated with this process include the use of highly corrosive mineral acids, environment pollution, large amount of water usage, over-degradation of cellulose, the requirement of large amounts of sulfuric acid, the production of a huge amount of salts for neutralization, and lower thermostability of the resultant CNCs because of the sulfate groups (Bashar et al., 2019; Leung et al., 2011; Zaini et al., 2019). Furthermore, the removal of lignin, hemicellulose, wax, and other non-cellulosic components is a prerequisite prior to the extraction of CNCs. In contrast to sulfuric acid hydrolysis, the APS oxidation is a simple and one-step procedure which can be used to prepare CNCs directly from a variety of cellulosic biomass without any pretreatment by removing non-cellulosic components as well as amorphous cellulose.

In general, two simultaneous actions occur during the APS oxidation: (1) removal of lignin, hemicellulose and other non-cellulosic components as well as removal of amorphous cellulose regions. (2) conversion of $-\mathrm{OH}$ groups at the $\mathrm{C} 6$ position to $-\mathrm{COOH}$ groups (Lam et al., 2013; Oun and Rhim, 2017). In fact, the breakdown of amorphous regions and cellulose oxidation through the formation of sulphate radical anion $\left(\mathrm{SO}_{4}^{\bullet-}\right)$, hydrogen peroxide $\left(\mathrm{H}_{2} \mathrm{O}_{2}\right)$ and hydrogen sulfate ion $\left(\mathrm{HSO}_{4}{ }^{-}\right)$are principal mechanism of the APS oxidation, as illustrated in Scheme. 1.

However, to the authors' knowledge, no report has been made about the preparation of carboxylated CNCs 


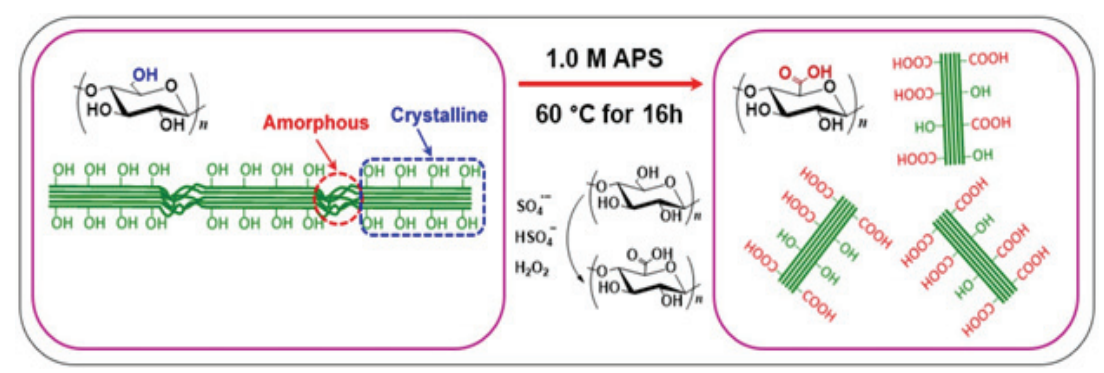

Scheme 1. The extraction pathway of carboxylated CNCs by the APS oxidation

from recycled MDF fiber by the APS oxidation. So, the main goal of this study was to characterize $\mathrm{CNCs}$ extracted from recycled MDF fiber using the APS oxidation. The properties of the obtained CNCs were characterized by transmission electron microscopy (TEM), conductometric titration, and ATR-FTIR spectroscopy. Prior to the $\mathrm{CNC}$ extraction, the chemical composition of the recycled MDF fibers were determined according to relevant standard methods.

\section{MATERIALS and METHODS}

\subsection{Materials}

Ammonium persulfate (APS; $\left(\mathrm{NH}_{4}\right)_{2} \mathrm{~S}_{2} \mathrm{O}_{8},>98.0 \%$ ); Sulfuric acid $\left(\mathrm{H}_{2} \mathrm{SO}_{4} ;>98.0 \%\right)$; Sodium hydroxide $(\mathrm{NaOH} ;>97.0 \%)$; Potassium sulfate $\left(\mathrm{K}_{2} \mathrm{SO}_{4} ;>99.0 \%\right)$; Mercuric oxide ( $\mathrm{HgO} ;>99.0 \%)$; Boric acid $\left(\mathrm{H}_{3} \mathrm{BO}_{3}\right.$;
$>99.5 \%)$ and Dextrose $\left(\mathrm{C}_{6} \mathrm{H}_{12} \mathrm{O}_{6} ;>98.0 \%\right)$ were purchased from Daejung Chemical Industry Co., Ltd., Korea. Sodium chlorite $\left(\mathrm{NaClO}_{2} ;>78.0 \%\right)$; Benzene $\left(\mathrm{C}_{6} \mathrm{H}_{6} ;>99.5 \%\right)$ and Ethanol $\left(\mathrm{C}_{2} \mathrm{H}_{5} \mathrm{OH} ;>99.5 \%\right)$ were purchased from Duksan Pure Chemicals Co., Ltd., Korea. Purified water by a reverse osmosis system with a conductivity of $6 \mu \mathrm{S} / \mathrm{cm}$ was obtained from Ultra-pure ROTech, Korea and was used for experiments. All the chemicals were analytical grade purity and were used as received without further purification. This work used recycled MDF fibers with about $1.08 \mathrm{~mm}$ length that had been prepared by the previous work (Hong et al., 2018).

\subsection{Preparation of carboxylated-CNCs}

A schematic diagram of the preparation of $\mathrm{CNCs}$ using APS oxidation is shown in Fig. $1.10 \mathrm{~g}$ of recycled MDF fibers as the starting material and $1 \mathrm{~L}$ of $1 \mathrm{M}$

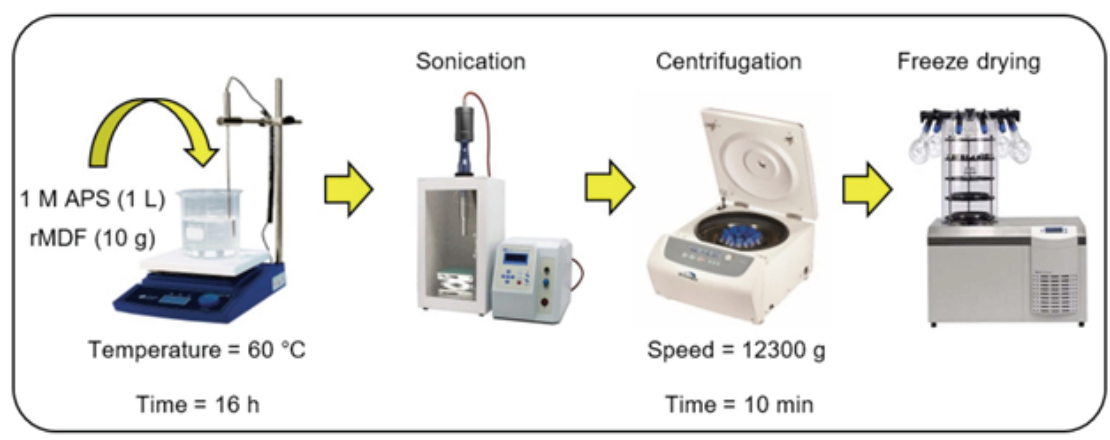

Fig. 1. Schematic diagram of the preparation of CNCs using the APS oxidation 
APS solution were introduced into a large beaker, onto a magnetic stirrer hotplate, equipped with a temperature controller. The mixture was heated at $60{ }^{\circ} \mathrm{C}$ for $16 \mathrm{~h}$ under constant mechanical stirring and an aluminum foil cover to prevent the evaporation of water. At the end of the desired reaction time, the vessel was placed in an ice bath to terminate the oxidation. The suspension was sonicated for $40 \mathrm{~min}$ using a high-power ultrasound processor (Sonomasher ULH-700S; ULSSO High-Tech Co., Cheongwon, Korea) at $20 \mathrm{kHz}$ frequency with a probe diameter of $1 \mathrm{~cm}$ and then centrifuged for 10 $\min$ at 12,300 g (Labogene 1580, Gyrozen Co., Ltd., Daejeon, Korea). After each centrifugation, the supernatant was decanted and replaced with deionized water. The centrifugation/ washing cycle was repeated until the solution $\mathrm{pH}$ was $\sim 4$. Then, the sample was sonicated in an ice bath $30 \mathrm{~min}$ before freeze-drying. The purified suspension was frozen at $-18^{\circ} \mathrm{C}$ overnight and freeze-dried under vacuum at room temperature to give white flaky solid freeze-dried CNCs.

\subsection{Characterization}

\subsubsection{Morphology of the isolated CNCs}

A transmission electron microscopy (TEM) (JEM2100F, Jeol Ltd., Tokyo, Japan) was used to observe the morphology of the isolated CNCs. For TEM analysis, the CNC suspension was diluted to a concentration of $0.01 \mathrm{wt} \%$ and sonicated for $10 \mathrm{~min}$. until the sample was uniformly dispersed. A droplet of this diluted suspension was dropped on a copper grid and allowed to dry at room temperature. Then a droplet of $3 \%$ uranyl acetate was applied to stain the specimen and the excess stain solution was removed with a filter paper. After that, the samples were allowed to dry at room temperature and the morphology and size of the CNCs were observed by TEM. The size of the CNCs was determined by measuring over $100 \mathrm{CNCs}$ using an image analysis software.

\subsubsection{Conductometric titration}

The content of carboxylic acid groups on the surface of CNC after the oxidation was determined by the conductometric titration method according to the procedure reported by Saito and Isogai (2004) with a minor modification. In a typical titration experiment, about $0.3 \mathrm{~g}$ freeze-dried CNC sample was dispersed in $55 \mathrm{ml} \mathrm{DI}$ water and $5 \mathrm{ml} \mathrm{NaCl}(0.01 \mathrm{M})$, and the mixture was sonicated for $10 \mathrm{~min}$ to obtain a very well-dispersed suspension. Then, the $\mathrm{pH}$ of the dispersion was adjusted to 2.5-3.0 by adding $0.1 \mathrm{M}$ $\mathrm{HCl}$ and the titration was performed using $0.01 \mathrm{M} \mathrm{NaOH}$ solution at the rate of $0.1 \mathrm{ml} / \mathrm{min}$ up to $\mathrm{pH} 10$. The conductivity was plotted against the volume of $\mathrm{NaOH}$ consumed, and the difference in $\mathrm{NaOH}$ volume between the start and the end of the plateau region was determined from where the regression lines were intersect, which represented the volume of $\mathrm{NaOH}$ used to neutralize the carboxylic acid groups. The results can be calculated using equation 1 :

$$
\text { Carboxyl content }\left(\frac{\mathrm{mmol}}{\mathrm{g}}\right)=\frac{\Delta \mathrm{VC}_{\mathrm{NaOH}}}{\mathrm{m}}
$$

where $\Delta \mathrm{V}$ is the difference in $\mathrm{NaOH}$ volume for the plateau region, $\mathrm{C}_{\mathrm{NaOH}}$ is the concentration of $\mathrm{NaOH}$, and $\mathrm{m}$ is the mass of the CNCs used in the titration.

\subsubsection{ATR-FTIR spectroscopy}

FTIR spectra were obtained using an ATR-FTIR spectroscopy (ALPHA-P model, Bruker Optics, Germany) equipped with an ATR universal accessory at room temperature. The spectra were recorded in absorbance mode over the wavenumber range of $400-4000 \mathrm{~cm}^{-1}$, with 32 scans for each spectrum and a scanning resolution of $4 \mathrm{~cm}^{-1}$.

\subsubsection{Characterization of recycled MDF fibers}

2.3.4.1 Dimensions of recycled MDF fibers

A light microscope (BX50, Olympus, Japan) was used 
to capture images of recycled MDF fibers for the measurement of their length and diameter. First, the fibers were suspended in deionized water and one single droplet of the diluted suspension was dropped on the microscope slide and covered with a cover glass. Then, images were taken at a suitable magnification at room temperature. Image analysis software (iSolution) was used to measure the length and diameter of each fiber. An average of 50 images was analyzed for the recycled MDF fiber.

\subsubsection{Chemical composition of recycled MDF fibers}

For chemical composition analysis, recycled MDF fibers were ground to powder with microfine grinder (MF10, IKA, Germany) and 40-60 mesh fractions were chosen for further use. The chemical composition of recycled MDF fibers was determined according to the relevant standards. Extractives content was measured with ethanol-benzene extraction according to TAPPI method T204 cm-97 (TAPPI, 1997). An amount of approximately $2 \mathrm{~g}$ of oven-dried recycled MDF fibers $\left(\mathrm{W}_{1}\right)$ was weighed out into an extraction thimble and placed into a Soxhlet extraction tubes connected to a pre-weighed flask containing $150 \mathrm{~mL}$ of the ethanol-benzene mixture at 1:2 v/v. The Soxhlet apparatus was placed, with condenser attached into the heating mantle and the temperature of the heating mantle was adjusted to provide a boiling rate that cycled the solvent at least six times per hour. After the extraction was completed, most of the solvent in the flask was evaporated leaving behind a few milliliters of solvent containing the extractives. The extractives were dried for 1 hour at $105^{\circ} \mathrm{C}$, then cooled in a desiccator and weighed $\left(\mathrm{W}_{2}\right)$. The extractive-free samples were used to determine lignin, holocellulose and $\alpha$-cellulose content of recycled MDF fibers. The extractive content was calculated as the Eq. (2):

$$
\operatorname{Extractives}(\%)=\frac{\mathrm{W}_{2}}{\mathrm{~W}_{1}} \times 100
$$

The ash content of the recycled MDF fibers was determined by the TAPPI T211 om-02 standard procedure (TAPPI, 2002). First, the ceramic crucibles were dried at approximately $525 \pm 25^{\circ} \mathrm{C}$ for $30 \mathrm{~min}$. Then they were put in a desiccator for $45 \mathrm{~min}$ and weighed. About $3 \mathrm{~g}$ of recycled MDF fibers $\left(\mathrm{W}_{1}\right)$ were placed in ceramic crucibles and then the crucibles were closed. They were put in a muffle furnace at $525 \pm$ $25{ }^{\circ} \mathrm{C}$ until all carbon was removed. The samples in the crucible were occasionally mixed. This process continued for at least $4 \mathrm{~h}$. All black particles should be lost and the samples should be completely white by the end of this time. After that, the sample was weighed $\left(\mathrm{W}_{2}\right)$. The ash content in samples was calculated as the Eq. (3):

$$
\operatorname{Ash}(\%)=\frac{\mathrm{W}_{2}}{\mathrm{~W}_{1}} \times 100
$$

The nitrogen content of the recycled MDF fibers was measured using the Kjeldahl method according to the TAPPI T418 cm-07 standard (TAPPI, 2007). About $2 \mathrm{~g}$ of recycled MDF fibers placed in a 500-mL Kjeldahl flask, $15 \mathrm{~g}$ of potassium sulfate and $0.7 \mathrm{~g}$ of mercuric oxide and $25 \mathrm{~mL}$ of concentrated sulfuric acid were added into the flask. The digestion was initiated by maintaining the temperature at about $150{ }^{\circ} \mathrm{C}$ until white fumes appeared. The temperature was then raised until the acid boils gently. The sample experiences distinct color changes and ultimately becomes colorless and the fuming ends. The digestion was maintained further at this temperature for an additional $1 \mathrm{~h}$. Once the digestion was completed, the digestion residue obtained was cooled and diluted with $300 \mathrm{~mL}$ DI water. The distillation was performed after the addition of $55 \mathrm{~mL}$ of $50 \% \mathrm{w} / \mathrm{v}$ sodium hydroxide to convert the ammonium sulphate to ammonia. One gram of dextrose was also digested simultaneously to constitute the blank test. 
Boric acid indicator solution was used to capture the ammonia gas. Distilled ammonia was absorbed on 50 $\mathrm{mL}$ boric acid indicator solution up to $150 \mathrm{~mL}$ and then diluted to about $250 \mathrm{~mL}$ with DI water. Finally, the nitrogen content was determined by titration with $0.1 \mathrm{~N}$ of hydrochloric acid after blank correction shown as the Eq. (4). During the titration, the color changed from green to gray and finally to purple.

$$
\operatorname{Nitrogen}(\%)=\frac{(1.4 \times \mathrm{V} \times \mathrm{N})}{\mathrm{W}} \times 100
$$

where $\mathrm{V}$ is volume of hydrochloric acid required to titrate the distillate $(\mathrm{mL}), \mathrm{N}$ is normality of hydrochloric acid $(\mathrm{N}), \mathrm{W}$ is weight of sample $(\mathrm{g})$, and 1.4 is equivalent weight of nitrogen $(\mathrm{g})$.

Acid-insoluble lignin content was determined using TAPPI standard T222 om-02 (TAPPI, 2002). Accordingly, about $1.0 \mathrm{~g}$ of oven-dry extractives-free sample was

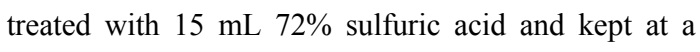
$20{ }^{\circ} \mathrm{C}$ water bath for $2 \mathrm{~h}$. Followed by the amount of $575 \mathrm{~mL}$ of DI water was added to the sample to make up a sulfuric acid concentration to $3 \%$ and kept under reflux for $4 \mathrm{~h}$. After the end of the reaction, the system was cooled for $30 \mathrm{~min}$ at room temperature. The hydrolyzed solution was filtered through a previously weighed sintered (medium) glass crucible and washed with DI water until the $\mathrm{pH}$ of filtrates was equal to that of the DI water. After these washings, the solid residue was dried at $105{ }^{\circ} \mathrm{C}$ for $24 \mathrm{~h}$ and used to determine the insoluble lignin (Eq. (5)).

$$
\operatorname{Lignin}(\%)=\frac{\mathrm{W}_{2}}{\mathrm{~W}_{1}} \times 100
$$

where $\mathrm{W}_{2}$ is weight of the oven-dry lignin residue $(\mathrm{g})$, and $\mathrm{W}_{1}$ is weight of the oven-dry extractives-free recycled MDF fibers $(\mathrm{g})$.
Holocellulose and $\alpha$-cellulose content were determined using a protocol established by Han and Rowell (Han and Rowell, 2008). Briefly, to $2.5 \mathrm{~g}$ of sample were added $80 \mathrm{~mL}$ of hot distilled water, $0.5 \mathrm{~mL}$ acetic acid, and $1 \mathrm{~g}$ of $\mathrm{NaClO}_{2}$ in a $250 \mathrm{~mL}$ Erlenmeyer flask and heated on a water bath at $70{ }^{\circ} \mathrm{C}$. After $60 \mathrm{~min}, 0.5$ $\mathrm{mL}$ of acetic acid and $1 \mathrm{~g}$ of $\mathrm{NaClO}_{2}$ are added. After each succeeding hour, fresh portions of $0.5 \mathrm{~mL}$ acetic acid and $1 \mathrm{~g} \mathrm{NaClO}_{2}$ are added with shaking. The addition of acetic acid and $\mathrm{NaClO}_{2}$ continued until the fibers were completely separated from the lignin (6 h). Then, the sample was left in a water bath overnight. At the end of the reaction, the sample cooled, and then the holocellulose filtered on filter paper using a Buchner funnel and then rinsed with acetone. Ultimately, the holocellulose dried in a vacuum oven at $105^{\circ} \mathrm{C}$ for 24 h. The mass difference before and after the acid treatment was used to calculate the holocellulose content according to Eq. (6).

$$
\text { Holocellulose }(\%)=\frac{\mathrm{W}_{2}}{\mathrm{~W}_{1}} \times 100
$$

where $\mathrm{W}_{2}$ is weight of the oven-dry holocellulose residue $(\mathrm{g})$, and $\mathrm{W}_{1}$ is weight of the original oven-dry extractives-free recycled MDF fibers (g).

The $\alpha$-cellulose content was determined as follows: First, 2 g moisture-free holocellulose sample was added to $10 \mathrm{~mL} 17.5 \% \mathrm{NaOH}$ solution at $20{ }^{\circ} \mathrm{C}$. Then, 5 $\mathrm{mL} 17.5 \% \mathrm{NaOH}$ solution was added to the mixture per 5 min until an ultimate volume of $25 \mathrm{~mL}$ was achieved. Following $30 \mathrm{~min}, 33 \mathrm{~mL}$ DI water was added and stirred for $1 \mathrm{~h}$. The filtered solid phase was washed, first once with $100 \mathrm{~mL} 8.3 \% \mathrm{NaOH}$ solution and then

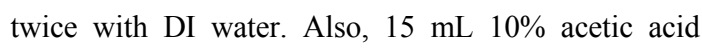
was poured onto the solid phase and washed until $\mathrm{pH}$ $\approx 7$. Finally, the sample dried in a vacuum oven at $105{ }^{\circ} \mathrm{C}$ for $24 \mathrm{~h}$. The $\alpha$-cellulose content was calculated 
according to the Eq. (7):

$$
\alpha-\text { cellulose }(\%)=\frac{\mathrm{W}_{2}}{\mathrm{~W}_{1}} \times 100
$$

where $\mathrm{W}_{2}$ is weight of the oven-dry $\alpha$-cellulose residue $(\mathrm{g})$, and $\mathrm{W}_{1}$ is weight of the original oven-dry holocellulose sample (g). Finally, the hemicellulose content was determined by subtracting the $\alpha$-cellulose content from the holocellulose content.

\section{RESULTS}

\subsection{Characterization of recycled MDF fibers}

Fig. 2 shows the optical micrographs of recycled MDF fiber. The length and diameter of these fiber were $434 \pm 148 \mu \mathrm{m}$ and $22.76 \pm 9.50 \mu \mathrm{m}$, respectively.

The mass fractions of cellulose, hemicellulose, lignin, extractives, ashes, and nitrogen of the recycled MDF fibers are summarized in Table 1. In lignocellulosic materials, the term "extractives" refer to a group of low molecular weight salts, fats, waxes, resins, carbohy-

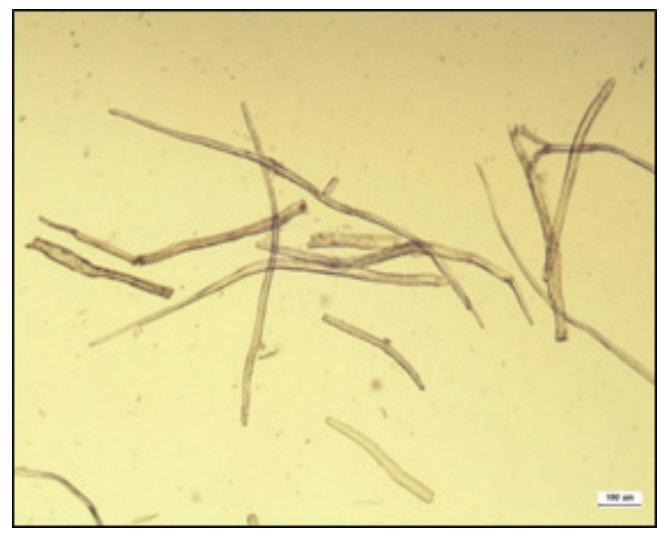

(a)
Table 1. Chemical composition of recycled MDF fibers

\begin{tabular}{cc}
\hline Constituents & Weight (\%) \\
\hline \hline Cellulose & $40.51(0.63)$ \\
Hemicellulose & $24.79(0.45)$ \\
Acid-insoluble lignin & $24.75(0.71)$ \\
Solvent extractives & $4.70(0.72)$ \\
Nitrogen & $2.70(0.03)$ \\
Ash & $0.55(0.06)$ \\
\hline
\end{tabular}

* Numbers in parentheses are standard deviations.

drates, and non-volatile hydrocarbons. The extractive content of the recycled MDF fibers was determined as $4.70 \%$ based the fiber dry mass. The analysis results also showed that recycled MDF fibers contained $0.55 \%$ ash and $2.70 \%$ nitrogen. It was believed that the nitrogen resulted from urea-formaldehyde (UF) resins used as adhesive for the MDF manufacture. The cellulose content of the recycled MDF fibers was $40.51 \%$, which was comparable with poplar (39\%), birch (41\%), pine (42\%) and lower compared to cedar (44\%), balsa (48\%), and spruce (49\%) (Madsen and Gamstedt, 2013). Meanwhile, the amounts of hemicellulose and lignin were $24.79 \%$ and $24.75 \%$, respectively.

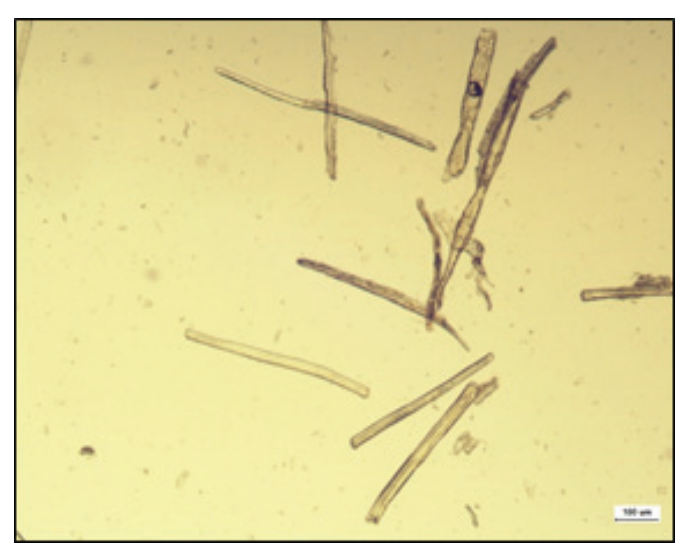

(b)

Fig. 2. Light micrographs of recycled MDF fiber. The scale bar is $100 \mu \mathrm{m}$. 


\subsection{Morphology of carboxylated CNCs}

Fig. 3 shows TEM images of the carboxylated CNCs from recycled MDF fibers at different magnifications. These images clearly show that the resultant CNCs have a rod-like morphology, confirming their successful extraction from recycled MDF fibers. The average diameter and length of extracted CNCs were at a nanometer scale. From the TEM analysis, the length of CNCs measured was an average of $167 \pm 47 \mathrm{~nm}$ with a range of 100 $295 \mathrm{~nm}$, and the diameter was an average of $8.24 \pm 2.28 \mathrm{~nm}$ with a range of $5 \sim 15 \mathrm{~nm}$, leading to an aspect ratio (L/D) of 20. These values
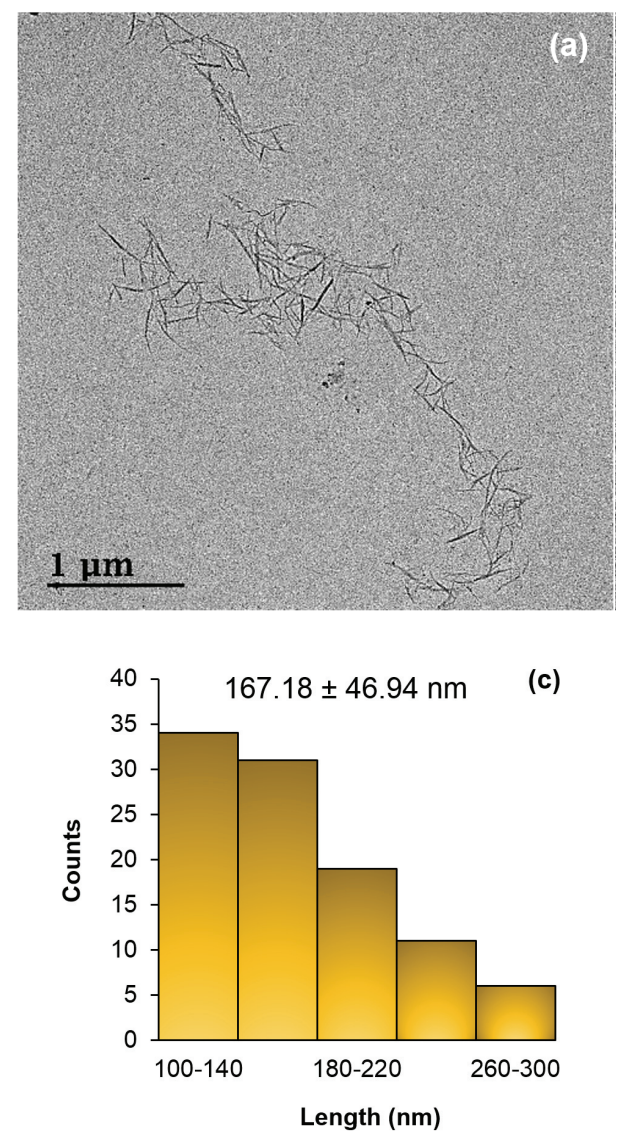

are similar to those reported in the literature for rod-shaped nanocrystals (Castro-Guerrero and Gray, 2014; Mascheroni et al., 2016; Rampazzo et al., 2017).

\subsection{Carboxyl content and degree of oxidation of the carboxylated-CNCs}

Fig. 4 shows the conductometric titration curve of the suspension of carboxylated CNCs after the APS oxidation. As exhibited in Fig. 4, the conductivity of the suspension is reduced as protons $\left(\mathrm{H}^{+}\right)$are consumed by $-\mathrm{OH}$ groups until the first equivalence point is reached.
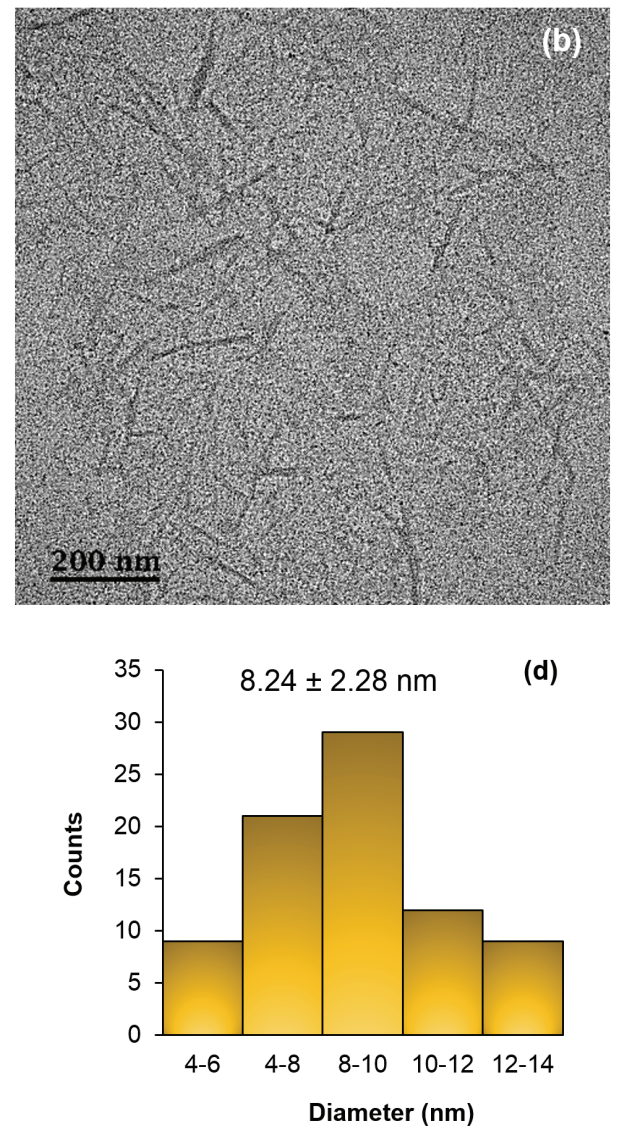

Fig. 3. TEM images of rod like carboxylated-CNCs obtained by the APS oxidation of recycled MDF fibers ( $a$ and $b$ ), and their length and diameter distribution ( $c$ and $d$ ) 


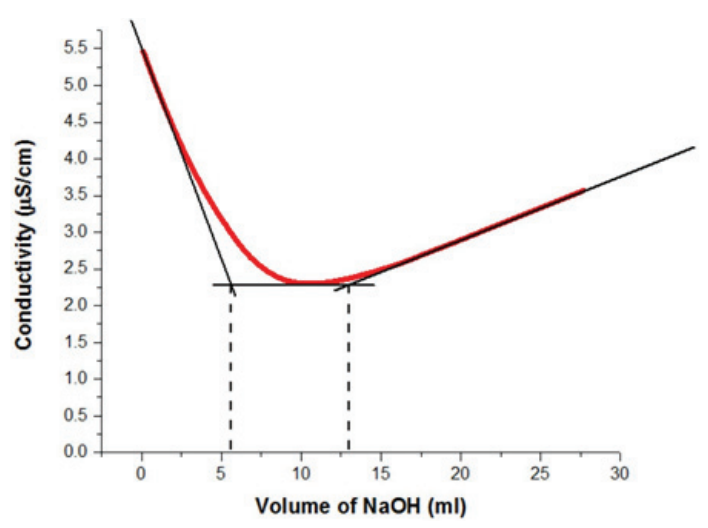

Fig. 4. Conductometric titration curve of the suspension of carboxylated cellulose nanocrystals after the APS oxidation.

All proton counterions of $\mathrm{CNCs}$ have been replaced with $\mathrm{Na}^{+}$counterions at the equivalence point. When sodium hydroxide added is in excess, the conductivity increases due to the presence of free hydroxyl groups in the suspension. It is worth noting that the slope of the acidic domain is steeper than that of the basic domain because the protons are more conductive than the hydroxyl groups (Foster et al., 2018). For the determination of the degree of oxidation (DO), the carboxylated $\mathrm{CNC}$ was subjected to $0.1 \mathrm{M} \mathrm{HCl}$ for complete protonation of the carboxyl groups. Then, the resulting carboxylated $\mathrm{CNC}$ was titrated with $\mathrm{NaOH}$ and the DO value was calculated using the following equation (Eq. (8)):

$$
\mathrm{DO}=\frac{162(\mathrm{C})\left(\mathrm{V}_{2}-\mathrm{V}_{1}\right)}{\mathrm{w}-36(\mathrm{C})\left(\mathrm{V}_{2}-\mathrm{V}_{1}\right)}
$$

where $C$ is the concentration of $\mathrm{NaOH}$ solution $(\mathrm{mol} / \mathrm{L})$; $w$ is the weight of the CNC samples $(\mathrm{g}) ; V_{l}$ and $V_{2}$ are the volumes of $\mathrm{NaOH}(\mathrm{L})$. The molecular weight of an anhydroglucose unit (AGU) is $162(\mathrm{~g} / \mathrm{mol})$. The molecular weight of an oxidized anhydroglucose unit in the form of sodium salt is $36(\mathrm{~g} / \mathrm{mol})$.

The DO stands for a ratio of the amount of oxidized
$-\mathrm{OH}$ groups to that of the un-oxidized groups on the anhydroglucose unit (Ye et al., 2018). The DO of CNCs depends not only on the source of cellulose but also on the reaction conditions (temperature, time and concentration of oxidizing agent) (Cheng et al., 2014; Leung et al., 2011). The conductometric titration showed that the carboxylated $\mathrm{CNC}$ sample prepared from recycled MDF fibers had the carboxyl content of $0.24 \mathrm{mmol} / \mathrm{g}$ and the degree of oxidation of 0.04 . This level is lower than the reported ones (CastroGuerrero and Gray, 2014; Mascheroni et al., 2016). The carboxyl content and DO for cotton was reported as $0.9 \mathrm{mmol} / \mathrm{g}$ and 0.13 , respectively, by CastroGuerrero and Gray (2014). According to Mascheroni et al. (2016), the carboxyl group content was 0.98 $\mathrm{mmol} / \mathrm{g}$ at the reaction temperature of $75^{\circ} \mathrm{C}$ and the DO was around 0.15. The DO of 0.096 for microcrystalline cellulose was reported by Lam et al. (2013). These results indicate that the carboxyl content and DO of nanomaterials depend on the sources of cellulose and reaction conditions. For example, Oun and Rhim (2017) reported that the DO of 0.24 for chitin nanocrystals, which was greater than the DO of 0.084 from cotton linter and 0.15 from microcrystalline cellulose, respectively, at the same isolation condition.

\subsection{ATR-FTIR analysis of recycled MDF fibers and carboxylated-CNCs}

Fig. 5 shows ATR-FTIR spectra of recycled MDF fibers and carboxylated-CNCs at $\mathrm{pH} 4$ and 7 after the APS oxidation. As expected, the carboxylated CNCs displayed absorption peaks that were characteristic of cellulose. According to Fig. 5a, recycled MDF fibers and carboxylated $\mathrm{CNCs}$ are characterized with absorbance peaks in the range $3600-3000 \mathrm{~cm}^{-1}$ assigned to the stretching vibration of hydroxyl groups of cellulose (Cheng et al., 2014; Hu et al., 2014; Oun and Rhim, 2017; Robles et al., 2015; Zhang et al., 

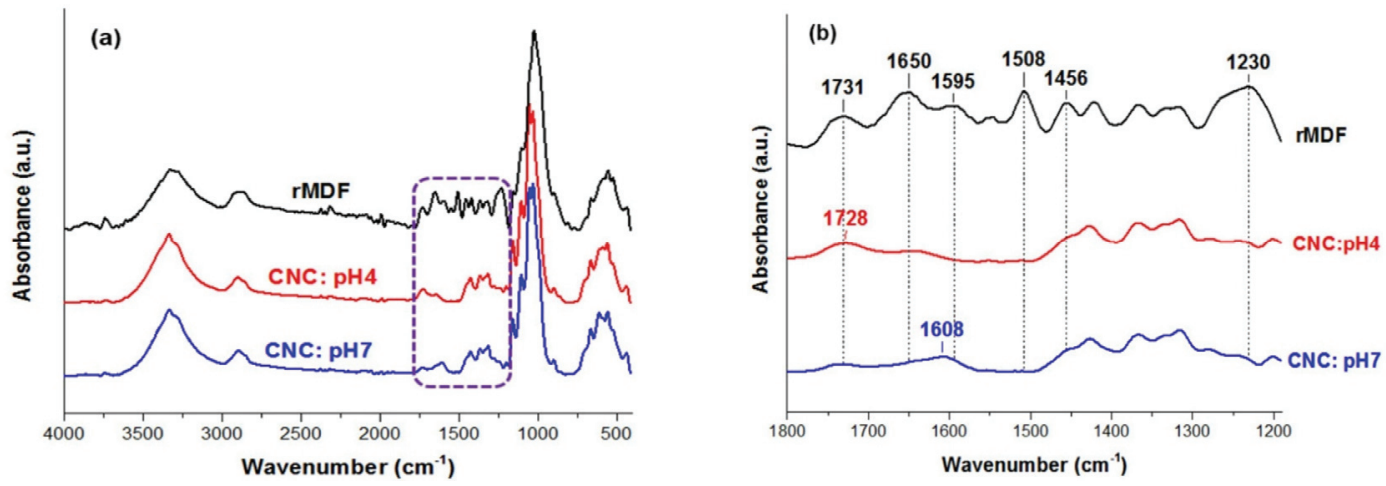

Fig. 5. ATR-FTIR spectra of recycled MDF fibers and carboxylated-CNCs obtained by the APS oxidation. (a) The whole spectra, and (b) enlarged spectra

2016), the band observed between 3000 and $2800 \mathrm{~cm}^{-1}$ region corresponds to asymmetric and symmetric $\mathrm{C}-\mathrm{H}$ stretching vibration (Cheng et al., 2014; Goh et al., 2016; Hu et al., 2014; Oun and Rhim, 2017; Zhang et al., 2016). Meanwhile, the peaks present at $\sim 1426$, 1367 and $1316 \mathrm{~cm}^{-1}$ in the all spectra are assigned to the symmetric bending of $\mathrm{CH}_{2}$, asymmetric deformations of $\mathrm{C}-\mathrm{H}$ and the bending vibrations of the $\mathrm{C}-\mathrm{H}$ and $\mathrm{C}-\mathrm{O}$ groups of the rings in polysaccharides, respectively (Cheng et al., 2014; Jiang et al., 2017; Oun and Rhim, 2017). Also, the peaks at $~ 1159,1106$ and $1055 \mathrm{~cm}^{-1}$, are attributed to the asymmetric COC bridge stretching, anhydroglucose ring asymmetric stretching, and COC pyranose ring stretching vibration in cellulose, respectively (Robles et al., 2015). These absorptions become more intense after oxidation by the APS oxidation, indicating the removal of non-cellulosic compounds during the APS oxidation process and an increase in the crystalline cellulose content. The peak observed at $\sim 1032 \mathrm{~cm}^{-1}$ could be assigned to the COC pyranose ring skeletal vibration (El Achaby et al., 2018). Furthermore, the peak observed at $900-895 \mathrm{~cm}^{-1}$ in all spectra could be attributed to the glycosidic bonds related to $\mathrm{C}_{1}-\mathrm{H}$ deformation vibrations which are symmetric in polysaccharides, represents the $\beta$ -glucosidic linkage between the anhydroglucose rings in the cellulose chains (El Achaby et al., 2018; Jiang et al., 2017; Liu et al., 2019; Ng et al., 2015; Oun and Rhim, 2017).

There is no peak in the $2800-2700 \mathrm{~cm}^{-1}$ range, indicating that intermediate aldehyde or ketone oxidation products are absent (Castro-Guerrero and Gray, 2014). According to Fig. 5b, the carbonyl peak at $1731 \mathrm{~cm}^{-1}$ in the recycled MDF fibers attributed to the $\mathrm{C}=\mathrm{O}$ stretching of the acetyl ester and uronic groups of hemicellulose and the ester linkage of the carboxylic groups of the ferulic and p-coumaric groups in lignin (Fortunati et al., 2016; Goh et al., 2016; Hafemann et al., 2019; $\mathrm{Ng}$ et al., 2015). On the other hand, in spectrum of the carboxylated $\mathrm{CNCs}$ at $\mathrm{pH} 4$, a new carbonyl peak was observed at $\sim 1728 \mathrm{~cm}^{-1}$, which was attributed to the $\mathrm{C}=\mathrm{O}$ stretching peak of the carboxyl groups $(-\mathrm{COOH})$, indicating that the functional groups were successfully introduced onto the surface of the prepared CNCs (Cheng et al., 2014; Goh et al., 2016; Liu et al., 2019; Mascheroni et al., 2016; Nascimento et al., 2016; Oun and Rhim, 2017; Ye et al., 2018; Zhang et al., 2016). In the case of the carboxylated $\mathrm{CNCs}$ at $\mathrm{pH} 7$, the band shifted to $1608 \mathrm{~cm}^{-1}$, which is responsible for sodium carboxylates $\left(\mathrm{COONa}^{+}\right)$(Oun and Rhim, 2017). The carboxylated CNCs did not show absorption peaks at 1595,1508 , or $1456 \mathrm{~cm}^{-1}$, 
which were related to lignin (Goh et al., 2016; Hu et al., 2014; Nascimento et al., 2016). In the recycled MDF fiber spectrum, the peak at $\sim 1508 \mathrm{~cm}^{-1}$ corresponds to the $\mathrm{C}=\mathrm{C}$ stretching vibration in the aromatic ring of lignin (Goh et al., 2016; Jiang et al., 2017), whereas the absence of this peak in the spectra of CNCs confirm the APS oxidation efficacy in the removing of lignin. The absorbance peaks at $1650 \mathrm{~cm}^{-1}$ and $1230 \mathrm{~cm}^{-1}$ was attributed to the $\mathrm{C}=\mathrm{C}$ stretching present in lignin components (Ng et al., 2015) and the $\mathrm{C}=\mathrm{O}$ stretching of hemicellulose, respectively (Fortunati et al., 2016). In the spectra of CNCs, the decrease in the intensity of both bands at $1731 \mathrm{~cm}^{-1}$ and $1230 \mathrm{~cm}^{-1}$ indicates the dissolution or removal of hemicellulose (Hafemann et al., 2019).

\section{CONCLUSION}

In this study, the carboxylated CNCs were directly isolated from recycled MDF fibers through simple and one-step APS oxidation and the following conclusions can be drawn:

1. The cellulose content of the recycled MDF fibers was in the range of $40-41 \%$, which makes it a good source of cellulosic material for different industrial uses.

2. TEM analysis of the resultant CNCs showed a rod-like whisker shape with a length of $100 \sim$ $295 \mathrm{~nm}$, diameter of $5 \sim 15 \mathrm{~nm}$, and an aspect ratio of around 20.

3. ATR-IR results confirmed the removal of the non-cellulosic compounds of recycled MDF fibers and also the presence of new bands at $\sim 1608$ $\mathrm{cm}^{-1}$ and $1728 \mathrm{~cm}^{-1}$ for $\mathrm{CNCs}$ with $\mathrm{pH} 4$ and 7 , respectively.

4. The use of recycled MDF fibers for the preparation of carboxylated CNCs showed a great potential for their future applications such as nanocomposites, sensors or packaging.

\section{ACKNOWLEDGEMENTS}

This work is supported by the Korea Research Fellow program of National Research Foundation (NRF). (Grant number: 2019H1D3A1A01070881).

\section{REFERENCES}

Aslan, D.I., Özoğul, B., Ceylan, S., Geyikçi, F. 2018. Thermokinetic analysis and product characterization of Medium Density Fiberboard pyrolysis. Bioresource Technology 258: 105-110.

Azambuja, R. da R., de Castro, V.G., Trianoski, R., Iwakiri, S. 2018. Recycling wood waste from construction and demolition to produce particleboards. Maderas: Ciencia y Tecnología 20: 681-690.

Bashar, M.M., Zhu, H., Yamamoto, S., Mitsuishi, M. 2019. Highly carboxylated and crystalline cellulose nanocrystals from jute fiber by facile ammonium persulfate oxidation. Cellulose 26: 3671-3684.

Castro-Guerrero, C.F., Gray, D.G. 2014. Chiral nematic phase formation by aqueous suspensions of cellulose nanocrystals prepared by oxidation with ammonium persulfate. Cellulose 21: 2567-2577.

Cheng, M., Qin, Z., Liu, Y., Qin, Y., Li, T., Chen, L., Zhu, M. 2014. Efficient extraction of carboxylated spherical cellulose nanocrystals with narrow distribution through hydrolysis of lyocell fibers by using ammonium persulfate as an oxidant. Journal of Materials Chemistry A 2: 251-258.

Cho, M., Park, B.D., Kadla, J.F. 2012. Characterization of electrospun nanofibers of cellulose nanowhisker/ polyvinyl alcohol composites. Journal of the Korean Wood Science and Technology 40: 71-77.

Couret, L., Irle, M., Belloncle, C., Cathala, B. 2017. Extraction and characterization of cellulose nanocrystals from post-consumer wood fiberboard waste. Cellulose 24(5): 2125-2137.

El Achaby, M., Kassab, Z., Aboulkas, A., Gaillard, C., 
Barakat, A. 2018. Reuse of red algae waste for the production of cellulose nanocrystals and its application in polymer nanocomposites. International Journal of Biological Macromolecules 106: 681691.

Fortunati, E., Benincasa, P., Balestra, G.M., Luzi, F., Mazzaglia, A., Del Buono, D., Puglia, D., Torre, L. 2016. Revalorization of barley straw and husk as precursors for cellulose nanocrystals extraction and their effect on PVA-CH nanocomposites. Industrial Crops and Products 92: 201-217.

Foster, E.J., Moon, R.J., Agarwal, U.P., Bortner, M.J., Bras, J., Camarero-Espinosa, S., Chan, K.J., Clift, M.J.D., Cranston, E.D., Eichhorn, S.J., Fox, D.M., Hamad, W.Y., Heux, L., Jean, B., Korey, M., Nieh, W., Ong, K.J., Reid, M.S., Renneckar, S., Roberts, R., Shatkin, J.A., Simonsen, J., Stinson-Bagby, K., Wanasekara, N., Youngblood, J. 2018. Current characterization methods for cellulose nanomaterials. Chemical Society Reviews 47: 2609-2679.

Goh, K.Y., Ching, Y.C., Chuah, C.H., Abdullah, L.C., Liou, N.S. 2016. Individualization of microfibrillated celluloses from oil palm empty fruit bunch: comparative studies between acid hydrolysis and ammonium persulfate oxidation. Cellulose 23: 379-390.

Gu, J., Hu, C., Zhong, R., Tu, D., Yun, H., Zhang, W., Leu, S.Y. 2017. Isolation of cellulose nanocrystals from medium density fiberboards. Carbohydrate Polymer 167: 70-78.

Gwon, J.G., Lee, D.B., Cho, H.J., Lee, S.Y. 2018. Preparation and characteristics of cellulose acetatebased nanocomposites reinforced with cellulose nanocrystals (CNCs). Journal of the Korean Wood Science and Technology. 46: 565-576.

Haeldermans, T., Claesen, J., Maggen, J., Carleer, R., Yperman, J., Adriaensens, P., Samyn, P., Vandamme, D., Cuypers, A., Vanreppelen, K., Schreurs, S. 2019. Microwave assisted and conventional pyrolysis of
MDF: Characterization of the produced biochars. Journal of Analytical and Applied Pyrolysis 138: 218-230.

Hafemann, E., Battisti, R., Marangoni, C., Machado, R.A.F. 2019. Valorization of royal palm tree agroindustrial waste by isolating cellulose nanocrystals. Carbohydrate Polymer 218: 188-198.

Han, J.S., Rowell, J.S. 2008. Chemical Composition of Fibers. Cellulose 283: 83-134.

Hong, M.K., Lubis, M.A.R., Park, B.D., Sohn, C.H., Roh, J. 2018. Effects of surface laminate type and recycled fiber content on properties of three-layer medium density fiberboard. Wood Material Science \& Engineering 0:1-9.

Hu, Y., Tang, L., Lu, Q., Wang, S., Chen, X., Huang, B. 2014. Preparation of cellulose nanocrystals and carboxylated cellulose nanocrystals from borer powder of bamboo. Cellulose 21(3): 1611-1618.

Jiang, H., Wu, Y., Han, B., Zhang, Y. 2017. Effect of oxidation time on the properties of cellulose nanocrystals from hybrid poplar residues using the ammonium persulfate. Carbohydrate Polymer 174: 291-298.

Ju, S.G. Roh, J.K. 2017. Manufacture of dyed recycling wood fiber using waste MDF. Journal of the Korean Wood Science and Technology. 45(3): 297-307.

Khanjanzadeh, H., Behrooz, R., Bahramifar, N., GindlAltmutter, W., Bacher, M., Edler, M., Griesser, T. 2018. Surface chemical functionalization of cellulose nanocrystals by 3-aminopropyltriethoxysilane. International Journal of Biological Macromolecules 106: $1288-1296$.

Karade, S.R. 2010. Cement-bonded composites from lignocellulosic wastes. Construction and Building Materials 24(8): 1323-1330.

Kim, A.R., Kim, N.H. 2019. Effect of heat treatment and particle size on the crystalline properties of wood cellulose. Journal of the Korean Wood Science and Technology 47(3): 299-310. 
Krause, K.C., Sauerbier, P., Koddenberg, T., Krause, A. 2018. Utilization of recycled material sources for wood-polypropylene composites: Effect on internal composite structure, particle characteristics and physico-mechanical properties. Fibers 6(4): 86

Lam, E., Leung, A.C.W., Liu, Y., Majid, E., Hrapovic, S., Male, K.B., Luong, J.H.T. 2013. Green strategy guided by Raman spectroscopy for the synthesis of ammonium carboxylated nanocrystalline cellulose and the recovery of byproducts. ACS Sustainable Chemistry \& Engineering 1: 278-283.

Lee, M., Prewitt, L., Mun, S.P. 2015. Environmental assessments of leachate from medium density fiberboard in a simulated landfill. Journal of the Korean Wood Science and Technology 43: 548-557.

Lee, M., Prewitt, L., Mun, S.P. 2014. Formaldehyde release from medium density fiberboard in simulated landfills for recycling. Journal of the Korean Wood Scienceand Technology 42: 597-604.

Leung, A.C.W., Hrapovic, S., Lam, E., Liu, Y., Male, K.B., Mahmoud, K.A., Luong, J.H.T. 2011. Characteristics and properties of carboxylated cellulose nanocrystals prepared from a novel one-step procedure. Small 7: 302-305.

Liu, Y., Liu, L., Wang, K., Zhang, H., Yuan, Y., Wei, H., Wang, X., Duan, Y., Zhou, L., Zhang, J. 2019. Modified Ammonium Persulfate Oxidations for Efficient Preparation of Carboxylated Cellulose Nanocrystals. Carbohydrate Polymer 229: 115572

Madsen, B., Ganstedt, E. K. 2013. Wood versus Plant Fibers: Similarities and Differences in Composite Applications. Advances in Materials Science and Engineering, ID 564346, doi:10.1155/2013/564346.

Mascheroni, E., Rampazzo, R., Ortenzi, M.A., Piva, G., Bonetti, S., Piergiovanni, L. 2016a. Comparison of cellulose nanocrystals obtained by sulfuric acid hydrolysis and ammonium persulfate, to be used as coating on flexible food-packaging materials. Cellulose 23(1): 779-793.
Nascimento, D.M. d., Almeida, J.S., Vale, M. do S., Leitão, R.C., Muniz, C.R., Figueirêdo, M.C.B. d., Morais, J.P.S., Rosa, M. de F. 2016. A comprehensive approach for obtaining cellulose nanocrystal from coconut fiber. Part I: Proposition of technological pathways. Industrial Crops and Products 93: 66-75.

Ng, H.M., Sin, L.T., Tee, T.T., Bee, S.T., Hui, D., Low, C.Y., Rahmat, A.R. 2015. Extraction of cellulose nanocrystals from plant sources for application as reinforcing agent in polymers. Composites Part B: Engineering 75: 176-200.

Oun, A.A., Rhim, J.W. 2017. Characterization of carboxymethyl cellulose-based nanocomposite films reinforced with oxidized nanocellulose isolated using ammonium persulfate method. Carbohydrate Polymer 174: 484-492.

Park, B.D., Um, I.C., Lee, S.Y., Dufresne, A. 2014. Preparation and characterization of cellulose nanofibril/polyvinyl alcohol composite nanofibers by electrospinning. Journal of the Korean Wood Scienceand Technology 42: 119-129.

Park, K.S., Kang, H.K., Park, S.H., Jung, S.C., Jeon, J.K., Lee, I.G., Kim, S.C., Park, Y.K. 2013. Conversion of waste medium density fiberboard over SAPO-11 catalyst. Journal of Nanoelectronics and Optoelectronics 8(6): 561-564.

Rampazzo, R., Alkan, D., Gazzotti, S., Ortenzi, M.A., Piva, G., Piergiovanni, L. 2017. Cellulose Nanocrystals from Lignocellulosic Raw Materials, for Oxygen Barrier Coatings on Food Packaging Films. Packaging Technology and Science 30: 645-661.

Robles, E., Urruzola, I., Labidi, J., Serrano, L. 2015. Surface-modified nano-cellulose as reinforcement in poly (lactic acid) to conform new composites. Industrial Crops and Products 71: 44-53.

Saito, T., Isogai, A. 2004. TEMPO-mediated oxidation of native cellulose. The effect of oxidation conditions on chemical and crystal structures of the water- 
insoluble fractions. Biomacromolecules 5: 19831989.

Seo, Y.R., Kim, B.J. Lee, S.Y. 2019. Effects of nanoclay and glass fiber on the microstructural, mechanical, thermal, and water absorption properties of recycled WPCs. Journal of the Korean Wood Science and Technology 47(4): 472-485.

Shang, T.X., Zhang, M.Y., Jin, X.J. 2014. Easy procedure to prepare nitrogen-containing activated carbons for supercapacitors. RSC Advances 4: 39037-39044.

Ye, S., Yu, H.Y., Wang, D., Zhu, J., Gu, J. 2018. Green acid-free one-step hydrothermal ammonium persulfate oxidation of viscose fiber wastes to obtain car- boxylated spherical cellulose nanocrystals for oil/water Pickering emulsion. Cellulose 25: 51395155.

Zaini, L.H., Febrianto, F., Wistara, I.N.J., Marwanto, N., Maulana, M.I., Lee, S.H., Kim, N.H. 2019. Effect of ammonium persulfate concentration on characteristics of cellulose nanocrystals from oil palm frond. Journal of the Korean Wood Scienceand Technology 47: 597-606.

Zhang, K., Sun, P., Liu, H., Shang, S., Song, J., Wang, D. 2016. Extraction and comparison of carboxylated cellulose nanocrystals from bleached sugarcane bagasse pulp using two different oxidation methods. Carbohydrate Polymer 138: 237-243. 